\title{
Epidemiological Evaluation of Intervention Program to Promote Mental and Sleep Health of Sports Athletes
}

\author{
Tetsuo Harada ${ }^{1}$, Kai Wada ${ }^{1}$, Osami Akimitsu ${ }^{1}$, Milada Krejci ${ }^{2,3}$, Teruki Noji ${ }^{4}$, \\ Miyo Nakade ${ }^{5}$ \& Hitomi Takeuchi ${ }^{1}$ \\ ${ }^{1}$ Laboratory of Environmental Physiology, Graduate School of Integrated Arts and Sciences, Kochi University, \\ Japan \\ ${ }^{2}$ Department of Health Education, Faculty of Education, University of South Bohemia, Jeronymova, Ceske \\ Budejovice, Czech Republic \\ ${ }^{3}$ University of Physical Education and Sport PALESTRA in Prague, Czech Republic \\ ${ }^{4}$ Department of Physical and Health Education, Faculty of Education, Kochi University, Japan \\ ${ }^{5}$ Department of Nutritional Management, Faculty of Health and Nutrition, Tokai-Gakuen University, Japan \\ Correspondences: Tetsuo Harada, Laboratory of Environmental Physiology, Graduate School of Integrated Arts \\ and Sciences, Kochi University, Kochi 780-8520, Japan. E-mail: haratets@kochi-u.ac.jp
}

Received: May 11, $2013 \quad$ Accepted: June 25, $2013 \quad$ Online Published: August 15, 2013

doi:10.5539/ijps.v5n3p155 URL: http://dx.doi.org/10.5539/ijps.v5n3p155

This study was financially supported by Academic Supporting Award by President of Kochi University (2009-2012: To T. Harada), Academic Supporting Award by Dean of Faculty of Education, Kochi University (2008-2009: To T. Harada) and awards from the Japan Society for the Promotion of Science (Award No. 22370089: To T. Harada, Award No. 23-10971 to K. Wada) (2010-2014).

\begin{abstract}
Our research group has went on several intervention programs which were applied to infants, elementary school and junior high school students and university sports-club students and also people who suffered disaster of Hanshin-Awaji Great Earthquake in 1995. All intervention programs were performed and are now going on to promote mental and physical health. The current intervention program focuses on the intervention which is based on a newly constructed series-of-leaflets for promoting sleep health entitled "Three great benefits due to 'Go to Bed Early, Get up Early and Do not Forget Breakfast!". These leaflets consist of four versions for parents of small children, athletes, women and people who suffered great disasters. In this study, we would like to focus on the results of three intervention studies to promote the athletes who are the members of succor team of Kochi University held in November of 2008 (Takeuchi et al., 2012), 2010 (Wada et al., submitted) and 2011 (Wada et al., unpublished; Harada et al.,. unpublished). All the three kinds of intervention seem to be effective for athletes to change their chronotype into morning-typed one, promote the sleep and mental health and finally improve their performance in playing sports.
\end{abstract}

Keywords: sports-men, morning-typed life, better performance, mental health, growth hormone, REM sleep, serotonin, melatonin, intervention

\section{Introduction}

This paper deals with the intervention programs which are educational methods to promote sleep and mental health and improve the sports performance of athletes. The main contents of the intervention are the tryptophan intake at breakfast and following exposure to sun lights. Moreover, incandescent light with lower color-temperature lights as lighting at night is recommended to keep melatonin secretion. The following four paragraphs are theoretical basements of these contents as intervention.

\subsection{Daytime Serotonin Secretion to Be Promoted}

The Tryptophan is an essential amino acid which can be absorbed exclusively from meals in humans. It is metabolized via 5-hydroxytryptamine (serotonin) to melatonin by a series of 4 enzymes in the pineal body (Moore et al., 2000; Zheng et al., 2004). Serotonin is known as a precursor to melatonin. A shortage of serotonin 
causes depression (including bipolar affective disorder: Mahmood \& Silverstone, [2001]), panic disorder, obsessive-compulsive disorder, sleep disorders and eating disorders (Suzuki, 2000) and induces aggression, anxiety/aggression-driven depression, impulsive behavior and suicidal attempts (Linnoila et al., 1993; Van Praag, 2001; Lindström et al., 2004). Serotonin thus has a strong relationship with mental health. Recently, serotonin reuptake inhibitors (SSRIs) have come to be widely used for the treatment of affective disorders including depression (Taylor \& Murray, 2006), although there are controversies whether SSRIs are effective or not for the treatment of depression in children and adolescents because of the shortage of coincident scientific evidences of SSRIs for the young humans (Deniau \& Cohen, 2005).

\subsection{Sunlight Exposure in the Morning Promoting Serotonin Synthesis}

Exposure to sunlight in the daytime appears to trigger synthesis of serotonin in the pineal body (Rosenthal et al., 1997). This action is hypothesized to occur mainly in the morning hours, because the amount of tryptophan consumed with supper has neither significant effects on the diurnal type scale scores (Torsvall \& Åkerstedt, 1980) nor an effect on sleep habits, as shown by another study on young Japanese children performed in 2005 (Harada et al., 2012).

\subsection{Serotonin Synthesis Can Be Promoted by the Exposure to Sunlight after Taking Breakfast}

Tryptophan intake at breakfast is effective for the onset and offset of sleep in young children (Harada et al., 2007). Moreover, questionnaire surveys showed that young children exposed to sunlight for more than 30 minutes after having sources of protein at breakfast are more morning-typed than those exposed for less than 30 minutes (Nakade et al., 2009), and that the more young children take vitamin B6 at breakfast, the more they exhibit morning typology (Nakade et al., 2012).

\subsection{Melatonin Synthesis from Serotonin Can Be Suppressed by Evening Lights with High Color Temperature from Fluorescent Lamp}

Melatonin is synthesized in the pineal body of the hypothalamic area and secreted at night. Melatonin level at serum can be well and positively correlates with that at saliva level (Laakso et al., 1990; Nagtegaal et al., 1998; Peuhkuri et al., 2012). Secretion of melatonin exhibits circadian rhythms and is suppressed by bright light (Burgess et al., 2001; Kubota, 2002). Even room lights such as fluorescent lamps can attenuate melatonin excretion duration at night (Harada, 2004; Gooley et al., 2011). This evening lights might include lights with high color temperature from the monitor of PC, TV-game, and mobile phone. These lights from the monitor are possible to delay the circadian phase, depress the melatonin level at night and reduce the sleep quality, although there have been only a few studies on the effect such lights on circadian phase (Harada et al., 2004) and REM sleep reduction (Higuchi et al., 2005).

The relationship between physical activities and sleep has been studied from a view-point of effective method as physical training and activities to promote sleep health. For example, thirty minutes of running in the morning during weekdays for 3 consecutive weeks impacted positively on sleep and psychological functioning in healthy adolescents (18 yrs old, half females) living in Switzerland compared with control subjects (no running trainings) (Kalak et al., 2012). Another Switzerland study on adolescents aged 17.2 years on average showed that compared with controls (4.69 hours physical-training per week), athletes (17.69 hours) reported better sleep patterns including higher sleep quality, shortened sleep onset latency, and fewer awakenings after sleep onset, as well as less tiredness and increased concentration during the day (Brand et al., 2010). Atkinson \& Davemme (2007) introduced in their review paper a number of physiologic relationships between the behaviors of sleep and exercise, and emphasized that the appropriate transition period between physical activity and sleep onset might be important for ensuring good sleep quality. However, there have been no challenges on whether promotion of sleep health via shifting to morning-typed life can improve the sports performance of athletes. This intervention program tries to promote the morning-typed life of athletes and this chronobiological approach challenges to improve the mental and sleep health and finally the athletes performance.

\section{Three Interventions for Athletes}

2.1 The First Intervention to Athletes, "Breakfast Contents and Following Exposure to Light" (Takeuchi et al., 2012)

This study was performed to clarify whether a combined intervention of the consumption of Tryptophan and Vitamin B6 at breakfast plus sunlight exposure after breakfast could effectively increase morningness in the participants of Japanese University sport club members (Fig. 1). The participants were 83 male members of the soccer team at an university (aged 18-22). All the participants are undergraduate students of The National University Cooperation Kochi University who had passed relatively severe entrance examination. The students 
were divided into three groups with equal numbers of the different chrono-types to eliminate bias. Participants in Group 1 (G1) had no intervention. Participants in Group 2 (G2) were asked to eat protein resources such as fermented soybeans and Vitamin B6 resources such as bananas at breakfast and were also asked to record their breakfast contents. Participants in Group 3 (G3) were asked to do the same as G2 plus expose themselves to sunlight after breakfast and record the exposure duration.

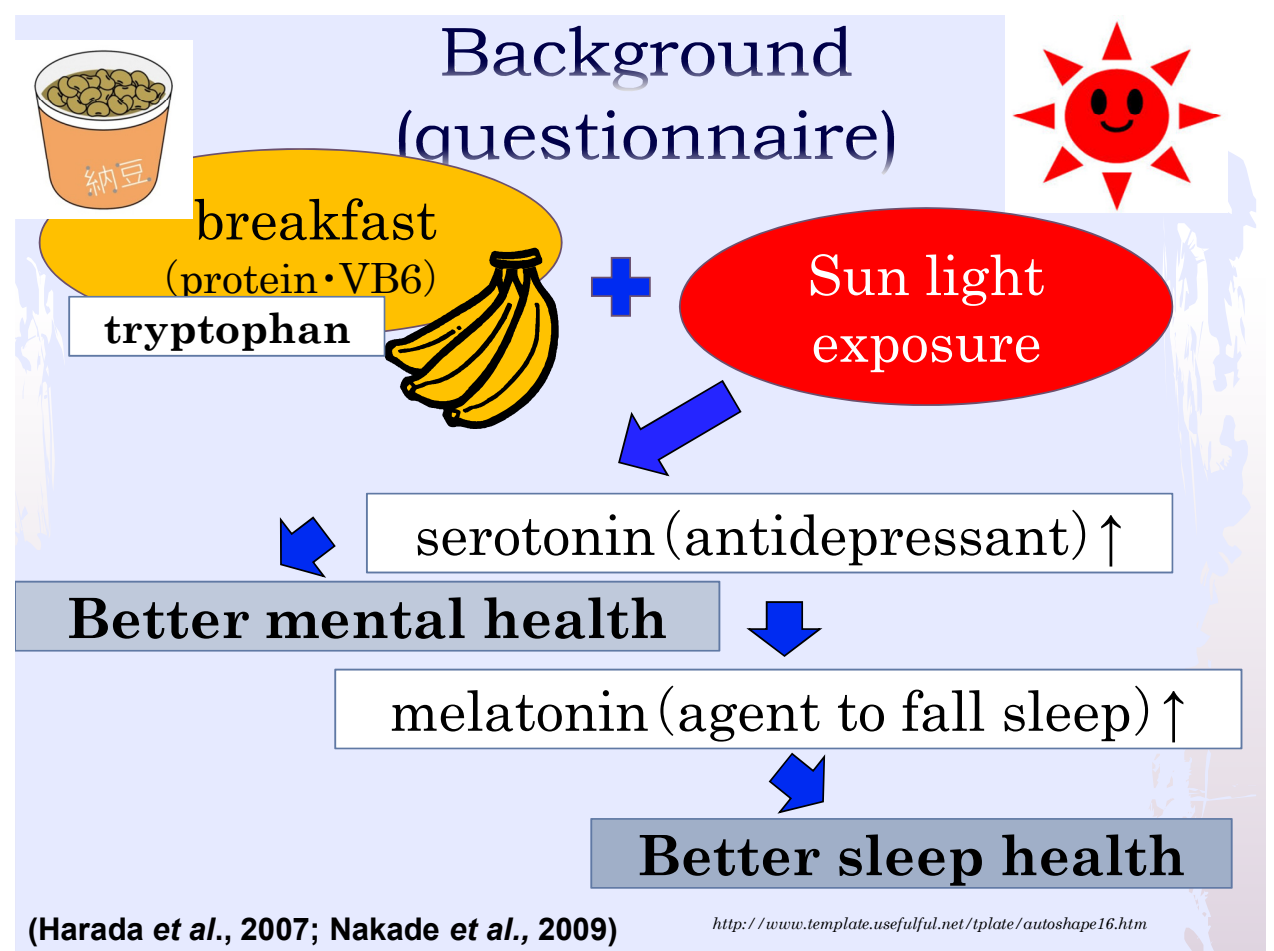

Figure 1. Schematic presentation of the theoretical mechanism of tryptophan consumption at breakfast and following exposure to sunlight to promote the sleep and mental health

\subsubsection{Survey on Lifestyle Habits (Integrated Self Assessment Questionnaire)}

This part included questions on eating habits, sleep habits (Shinomiya et al., 2004) and mental health, a part of an integrated questionnaire on sleep habits and diurnal rhythms (Harada et al., 1998) and the Diurnal Type Scales by Torsvall \& Åkerstedt (1980).

\subsubsection{Food Frequency Questionnaire}

A Food Frequency Questionnaire (FFQ) (Yoshimura \& Takahashi, 2007)*(self-assessment questionnaire) was administered before and after the month-long intervention period (Oct, 2008 and Jan, 2009), and the effectiveness of intervention was evaluated by the integrated questionnaire just before the intervention and 1 month after that. Participants were asked to answer a questionnaire about daily diet as the FFQ method. Participants described their student number every occasion when they answered the questionnaire to identify the individual for detailed analysis and to help them improve their nutrition in the future.

*FFQ is an acronym for Food Frequency Questionnaire Based on Food Groups. It is a survey on frequency of consumption that assesses daily diet (over the past one or two months) based on simple questions on 10 types of cooking methods and 29 different food groups. More specifically, frequency of consumption and portion size over the past 1-2 months was measured in one week units to estimate intake of food groups and nutrition. The validity is being tested (Takahashi et al., 2001).

2.1.3 Survey on the Frequency in Which the Intervention Was Carried out and the Effects of the Frequency (Self Assessment Questionnaire $=$ Personal Evaluation of the Intervention)

Immediately after the intervention period, participants answered the question how frequently they carried out the month-long intervention program from 1 to 100 (100 points for perfectly complying with the proposal without 
missing a single day; 0 points for complete lack of compliance with the proposal in each intervention group). Points evaluated included breakfast related intervention (only for G2, G3) as the evaluation of how many days the participants ate foods including high amounts of Tryptophan and Vitamin B6 at breakfast. The evaluation also included how many days they were exposed to sunlight immediately following breakfast only for G3. Follow up surveys (1)' and (2)' consisted of the same questions as the preliminary surveys (1) and (2) and were administered one month later of the intervention (Figure 1). The question on how extent participants are satisfied on carrying out the intervention was administered only to G2 and G3.

Among the FFQ data, this study used only the data about staple foods (grains: rice, bread, noodles), main dishes (meat, fish, soy products) and side dishes (brightly colored vegetables, other vegetables, mushrooms) from which we could calculate intake amounts for each of the three meals. The intake of Trp were estimated and compared between before and after the intervention. Trp and protein intakes at breakfast were calculated using staple food (grains: rice, bread, noodles) + main dish (meat, fish, soy products) + side dish (brightly colored vegetables, other vegetables, mushrooms). Method for calculation of the estimated tryptophan intake was authorized one in Nakade et al. (2012).

\subsubsection{Results}

Evening-typed participants who occupied $50 \%$ of all participants before the intervention in G2 and G3 significantly shifted to more morning-typed (Fig. 2) two months after the intervention. For the evening-typed participants who occupied $50 \%$ of all participants in G2 and G3, a significant and positive correlation was shown between the change in Trp amount consumed at breakfast and the change in M-E score (more Trp consumption and shifting to morning-type) before and after intervention (Fig. 3). Based on the correlation analysis, the consumption of Trp at breakfast might be hypothesized to cause a shift in circadian typology of university students to be more morning-typed.

\section{A. Individual comparison between before and after the intervention}
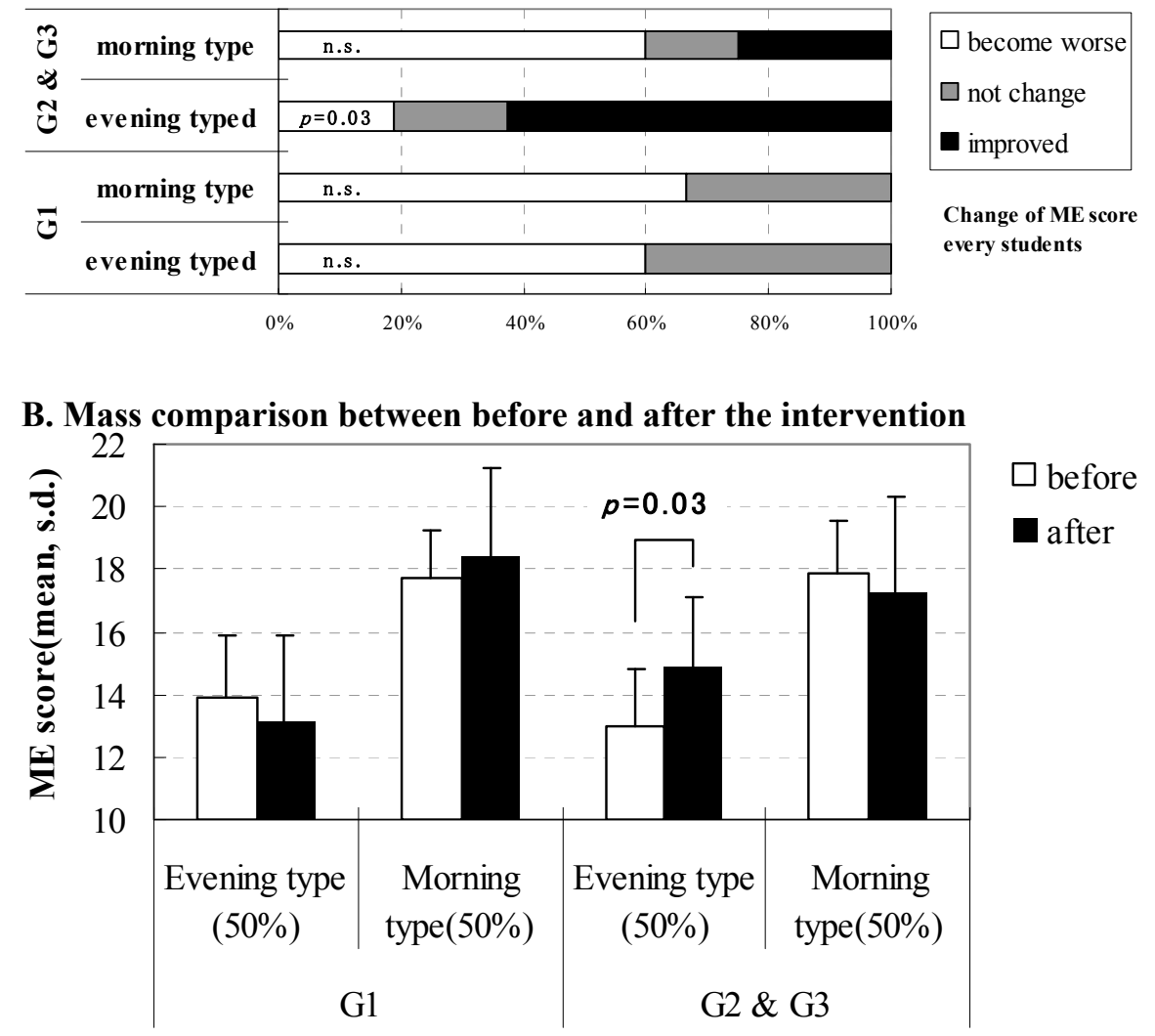

Figure 2. Half of the students who were evening-typed in the ME distribution before the intervention in G2 and G3 shifted to more morning-typed after the intervention

(Wilcoxon signed-ranks test: $\mathrm{z}=-2.19, p=0.03)$. Before: before intervention; After: 2 months after intervention $\square$ : Mean Before $\mathbf{m}:$ Mean After (Takeuchi et al., 2012) 
Sleep quality (Monroe, 1967) was significantly improved after the intervention in $\mathrm{G} 3(\mathrm{p}=0.03)$ and tended to be so in $\mathrm{G} 2(\mathrm{p}=0.08)$, while it was similar to that before intervention in $\mathrm{G} 1(\mathrm{p}=0.28)$. The frequency to become angry or irritated was lower after intervention than before it in $\mathrm{G} 2(\mathrm{p}=0.02)$ and $\mathrm{G} 3(\mathrm{p}=0.049)$, whereas there was no difference in the mental health in $\mathrm{G} 1(\mathrm{p}=0.94)$. These results could imply that the control group of $\mathrm{G} 1$ had no effects of the "time course of 4 months" from the beginning of October 2008 to the beginning of February 2009 or seasonal aspects on the diurnal type scale, sleep quality and mental health.

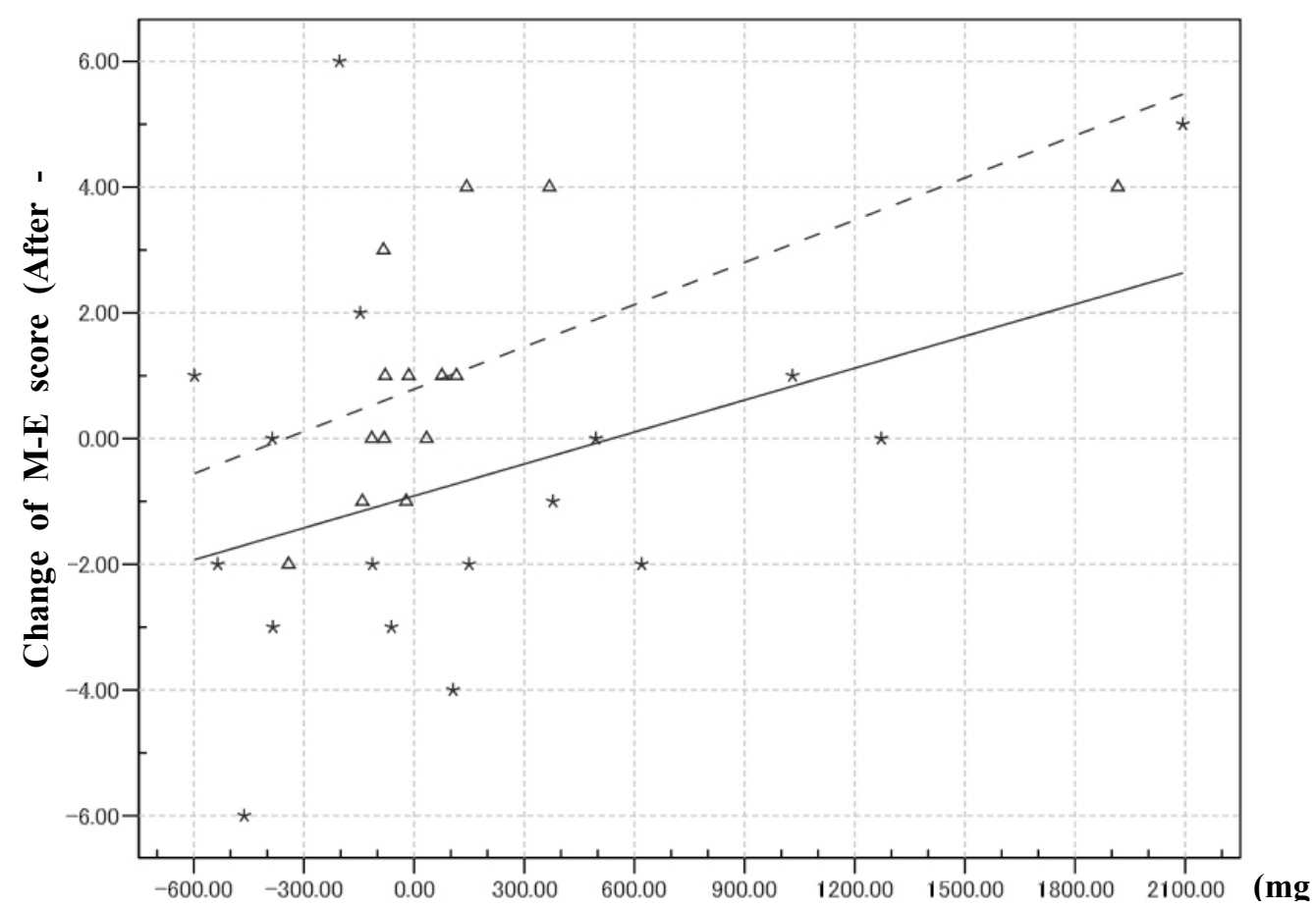

Change of Trp intake from breakfast

Figure 3. Correlation between change of M-E score and Trp value from breakfast (G2 \& G3)

For the evening-typed $50 \%$ of all participants in $\mathrm{G} 2$ and G3, a significant and positive correlation was shown between change in Trp amount consumed at breakfast and change in M-E scores before and after intervention (Pearson's $\mathrm{r}=0.612, p=0.020$ ). However, the morning-typed $50 \%$ of participants did not show significant correlation $(\mathrm{r}=0.405, p=0.106)$.

$\triangle:$ evening-typed $50 \%$ participants in the ME distribution before the intervention

$\star$ : morning-typed $50 \%$ participants in the ME distribution before the intervention

(Takeuchi et al., 2012)

2.2 The Second Intervention to Athletes as "Breakfast Contents, Following Exposure to Light" and Using Orange-Color Lights from Light-Bulbs as Night Lighting (Wada et al., 2013)

\subsubsection{Theoretical Basement}

The correlation between tryptophan rich breakfast and following exposure to sunlight and the morning type of Japanese infants (Harada et al., 2007) can be based on the following hypothesis. "A high concentration of serotonin in the brain and high concentration of plasma melatonin at night can induce earlier fall-in-sleep" (Fig. 1). However, this high melatonin-concentration can be depressed by the fluorescent lamps which are being used by most of all Japanese homes.

\subsubsection{Participants and Methods}

The intervention program was administered to 94 subjects (male, 19-22 years old, average age: 20.33) belonging to Kochi University soccer club. 63 subjects participated in the intervention program. They were divided into three groups (G1 [Photo 1-A], $\mathrm{n}=20$ : no intervention; G2 [Photo 1-A], $\mathrm{n}=22$ : asked to have protein-rich foods 
such as fermented soybeans and vitamin B6-rich foods such as bananas at breakfast and sunlight exposure after breakfast; G3 [Photo 1-B], $\mathrm{n}=21$ : the same contents as G2 and incandescent light exposure at night). All the members had used fluorescent lamps (white light) for the lighting at night. There were no significant differences among the body height, body mass, and age of the three groups. To estimate the effects of the one month interventions, melatonin in salivary collected was measured around 11:00 p.m. three times, just before the intervention, at a mid-point and on the last day of the 1 month intervention.

A

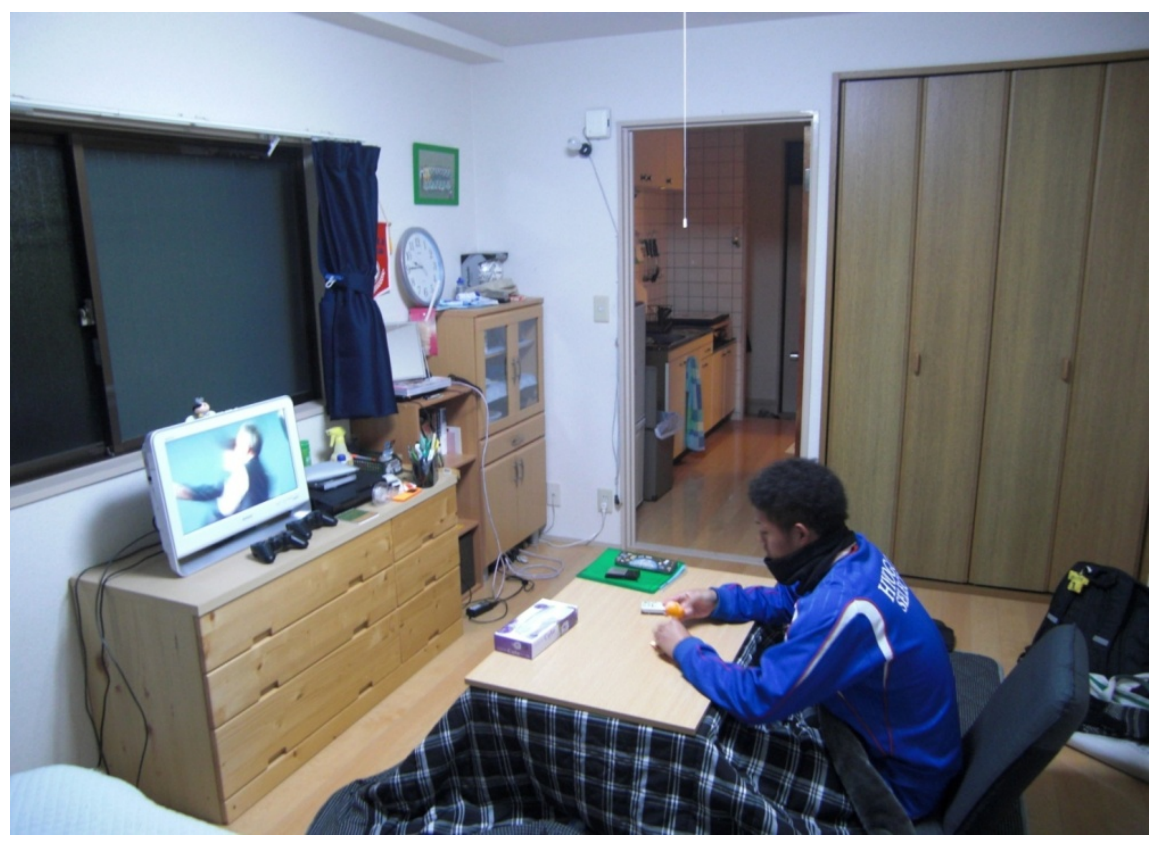

B

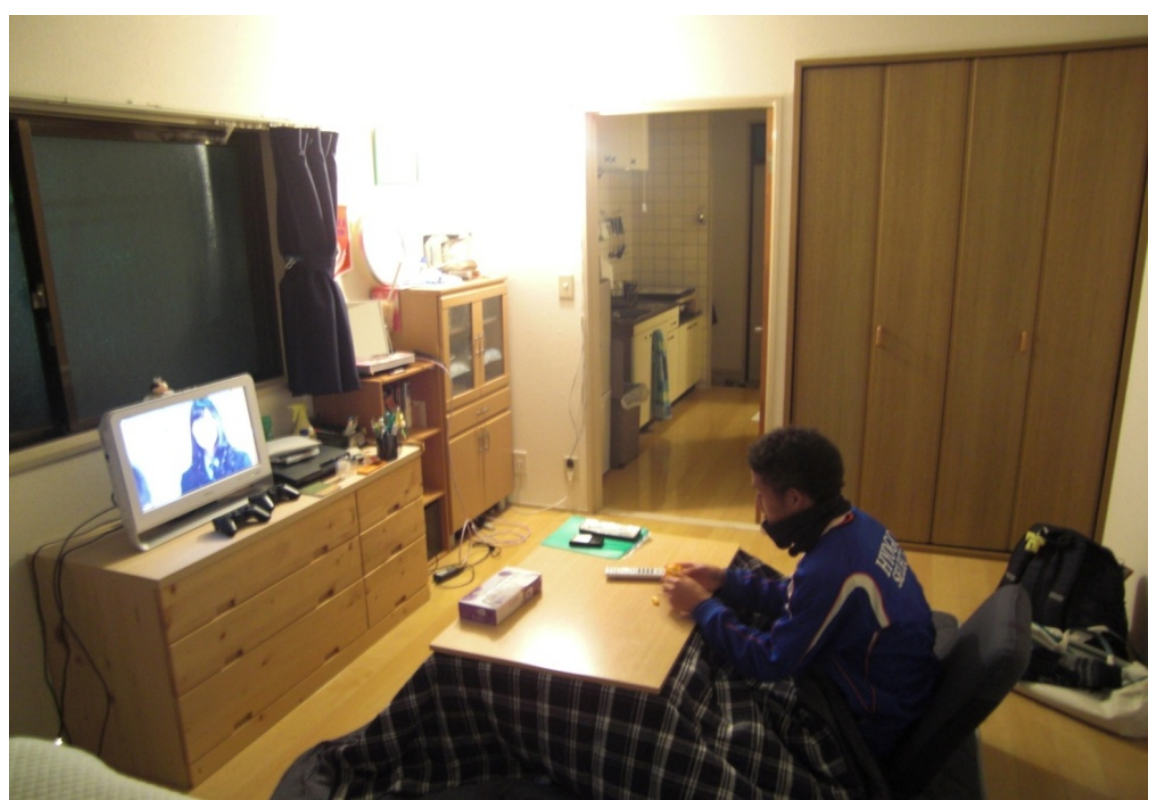

Photo 1. Examples of night time lighting for Group 1 and Group 2 (A) and Group 3 (B) during the intervention 1 month

(A): fluorescent lamp with higher color-temperature lights; (B): Incandescent light with lower color-temperature lights 
A

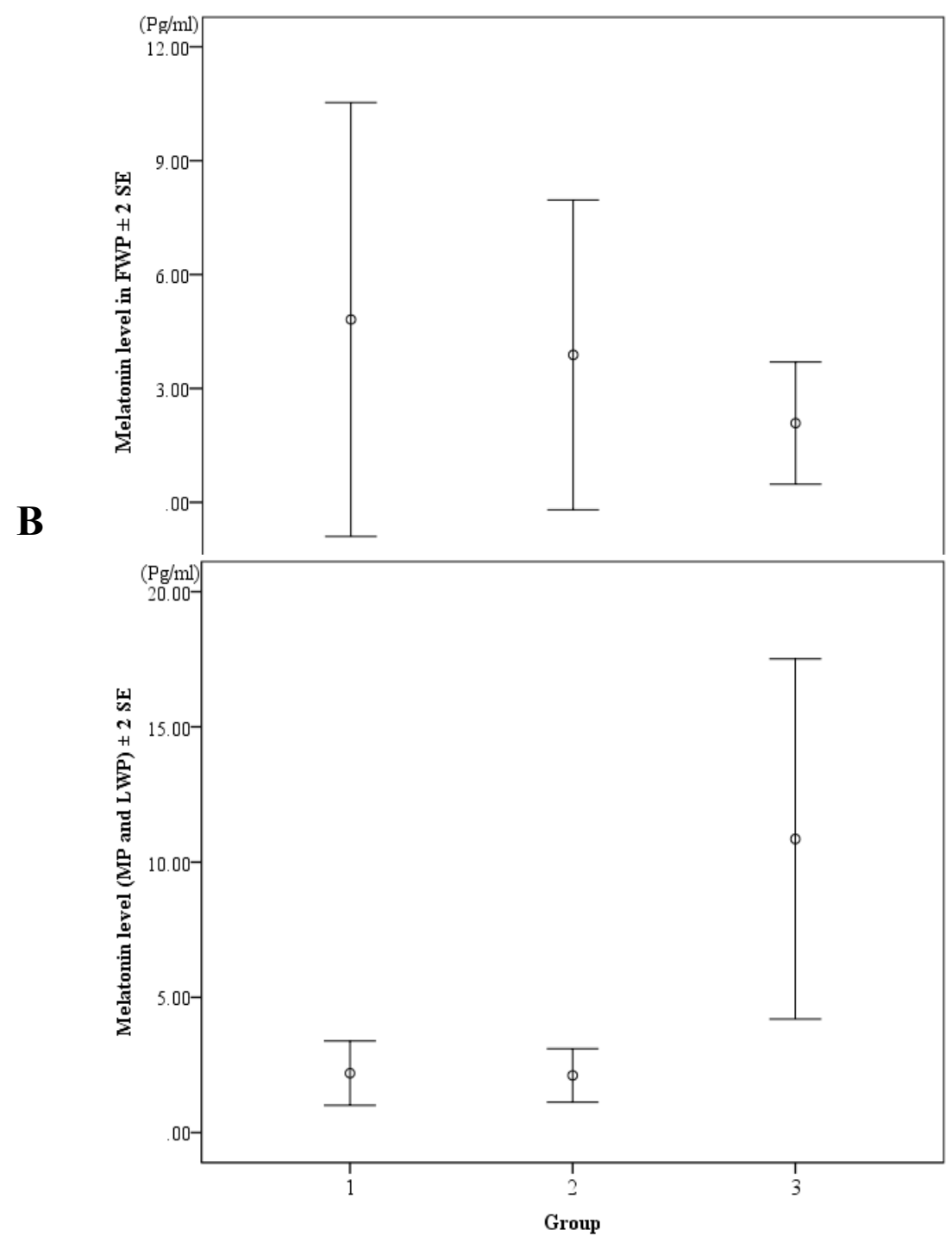

Figure 4. Comparison of salivary melatonin concentration among the three groups

Group 1: no intervention; Group 2: Recommendation of high protein breakfast and exposure to sunlight; Group 3: Same as Group 2 plus the recommendation of exposure to low color temperature light emitted from an incandescent light bulb. A: Melatonin level in the saliva collected on the day just before the intervention (Kruskal Wallis test: $\chi^{2}$-value $=0.92, \mathrm{df}=2, \mathrm{p}=0.63$ ); B: Melatonin in the saliva collected at the mid-point and on the day before the last day of the intervention(Bonferroni multiple comparison test: G1 versus G3, $p=0.018$; G2 versus $\mathrm{G} 3, \mathrm{p}=0.011$ ).

\subsubsection{Results}

In G3, there was significantly positive correlation between total hours when the participants spent under incandescent light at night and the frequency to feel deep sleep $(\mathrm{p}=0.034)$ during the last week. The salivary melatonin concentration of G3 was significantly higher than the melatonin level of G1 and G2 in combined salivary samplings at the mid-point and on the day just after the 1 month intervention ( $\mathrm{p}=0.018)$ (Fig. 4-A), whereas no such significant differences were shown on the day just before the start of the intervention period $(\mathrm{p}=0.63)$ (Fig. 4-B). The integrative intervention on breakfast, morning sunlight and evening-lighting may be effective for students including athletes to keep higher melatonin secretion at night which seems to induce easy introduction of the night sleep and higher sleep-quality. 
2.3 The Third Intervention to Athletes Using the Leaflet (Harada et al., 2011) for Athletes "Three Benefits for Athletes Due to 'Go to Bed Early, Get up Early and Do not Forget Breakfast!' (Wada et al., Unpublished; Takeuchi et al., Unpublished)

Table 1. Questions: How was your current soccer performance which could be evaluated by 11 elements, changed in comparison with tat just before the intervention period?

\begin{tabular}{|c|c|c|c|c|}
\hline & $\leftarrow$ Improved------ & - & -------------------------Rece & \\
\hline 1. Judgment of the situation in play & (1) quicker & (2) a little bit quicker & (3) a little bit delayed & (4) delayed \\
\hline 2. Field of vision in play & (1) broader & (2) a little bit broader & (3) a little bit narrower & (4) narrower \\
\hline 3. Moving legs felt in play & (1) heavier & (2) a little bit heavier & (3) a little bit lighter & (4) lighter \\
\hline 4. The first touch to the ball & (1) more skillful & (2) slightly more skillful & (3) slightly less skillful & (4) less skillful \\
\hline 5. Rudimentary errors & (1) decreased & (2) a little bit decreased & (3) a little bit increased & (4) increased \\
\hline 6. Irritation in play & (1) decreased & (2) a little bit decreased & (3) a little bit increased & (4) increased \\
\hline 7. Shortage of stamina & (1) decreased & (2) a little bit decreased & (3) a little bit increased & (4) increased \\
\hline 8. Injury in play & (1) decreased & (2) a little bit decreased & (3) a little bit increased & (4) increased \\
\hline 9. Body balance in play & (1) improved & (2) a little bit improved & (3) a little bit receded & (4) receded \\
\hline 10. Precision of long kick & (1) higher & (2) a little bit higher & (3) a little bit lower & (4) lower \\
\hline 11. Motivation for training & (1) higher & (2) a little bit higher & (3) a little bit lower & (4) lower \\
\hline
\end{tabular}

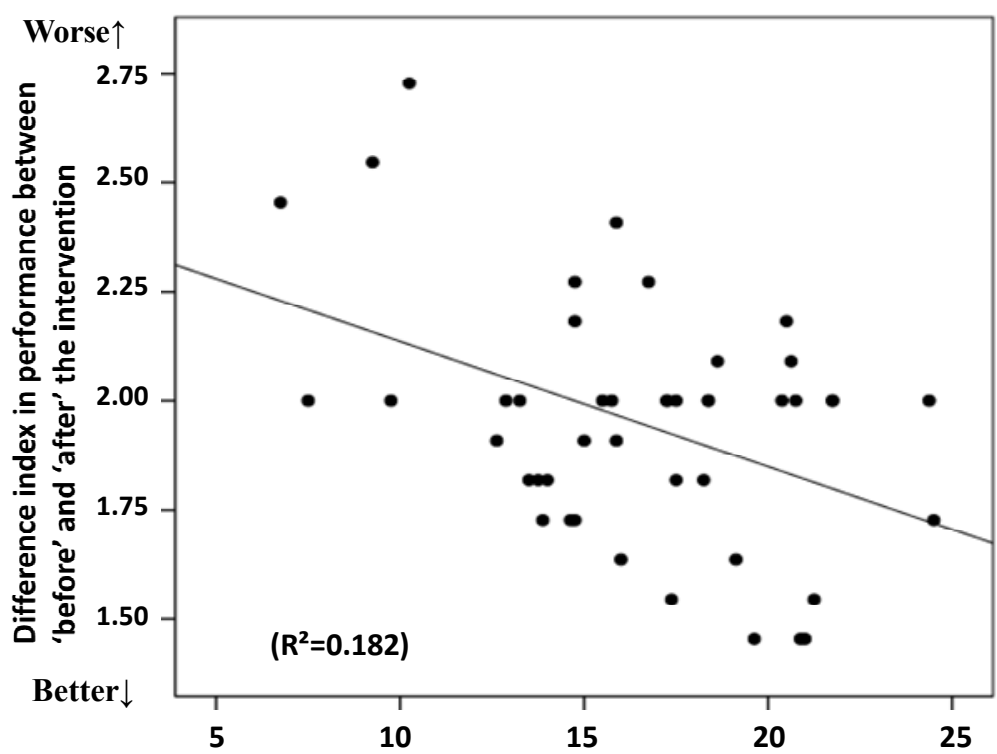

Total index of implementation of 7 kinds of intervention issues for one month

Figure 5. The implementation of 7 kinds of intervention issues for one month seems to be effective for improvement of soccer performance (Pearson's correlation test:

$$
\mathrm{r}=-0.426, \mathrm{p}=0.003 \text { ) }
$$




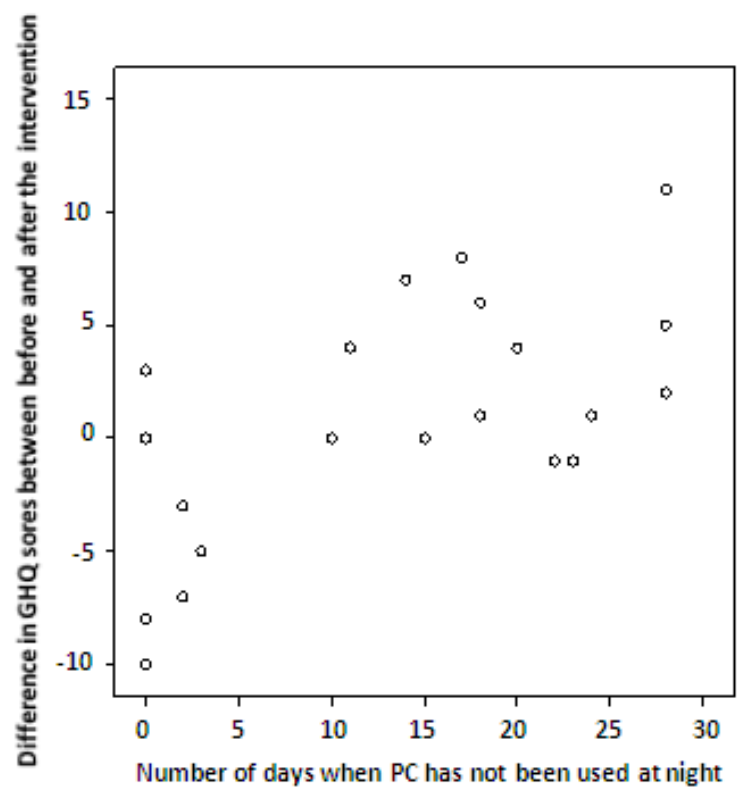

Figure 6. Mental health was improved by the no usage of PC at night during the intervention period of one month in the soccer team, as Group 3 which ranked the third in accordance with total performance ability (Pearson's correlation test: $\mathrm{r}=0.64, \mathrm{p}=0.001, \mathrm{n}=22$ ) (GHQ: The General Health Questionnaire)

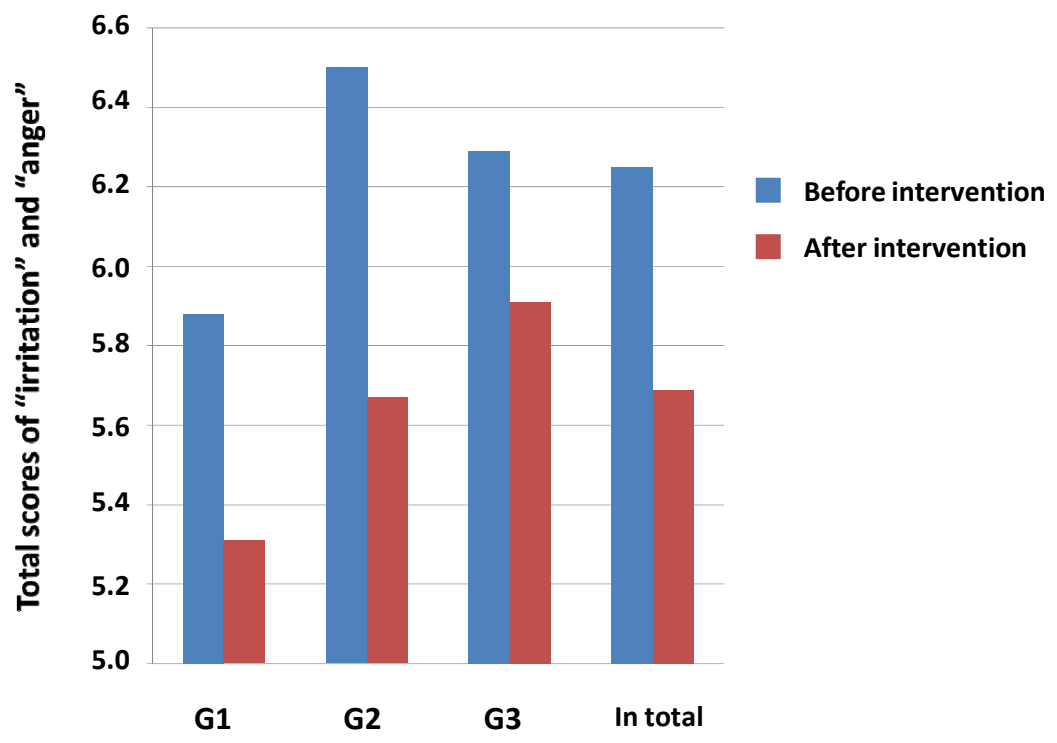

Figure 7. Improvement of mental health on "irritation" and "anger" due to the intervention for one month The improvement was significant only in the soccer team, Group 2 which ranked the second in accordance with total performance ability (Wilcoxon-test: Group 1 which ranked the first, $\mathrm{z}=-1.651, \mathrm{p}=0.099$; Group $2, \mathrm{z}=-2.126$, $\mathrm{p}=0.033$; Group 3 which ranked the third, $\mathrm{z}=-1.365, \mathrm{p}=0.172$ ) 


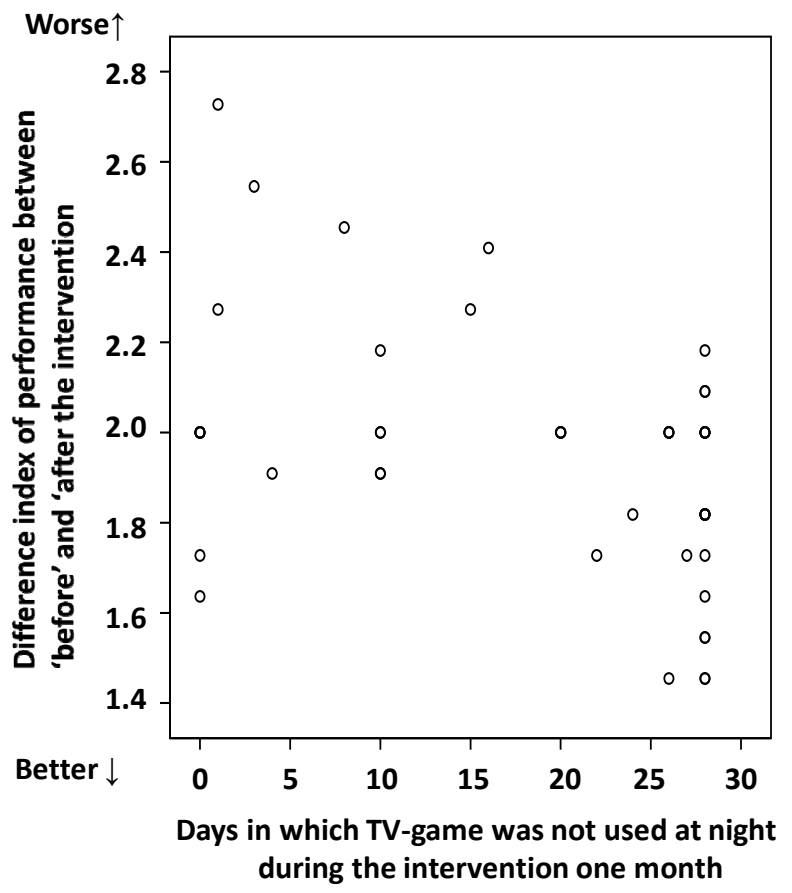

Figure 8. TV-game limitation at night may improve the soccer performance

All soccer team members ( 84 males aged 18-22 yrs) attending the Kochi University were asked to follow the contents of the leaflet for athletes "three benefits for athletes due to 'Go to Bed Early, Get up Early and Do not Forget Breakfast!' for one month of mid November to mid December 2011. Integrated questionnaire was administered before the intervention, just after the intervention and three months after the intervention. During one month intervention, sleep diary and meal contents survey were applied to the participants every day. Just after the intervention, the number of days when they could follow each of the seven contents (1. Exposure to sunlight early in the morning, 2. Exposure to sunlight after breakfast, 3. Exposure to orange-colored lights from light bulb as night lighting, 4. Consumption of protein resources at breakfast, 5. Limitation of using TV-Game at night, 6. Limitation of using PC at night, 7. Limitation of watching TV at night) of intervention was recorded. Change in each of 11 elements of performance quality (Table 1) from the beginning of intervention was subjectively evaluated at one month later. The sum of change-values in 11 elements was presented as index of change in soccer-performance quality. The soccer team members were divided to three groups which were ranked in accordance with total performance ability (G1: ranked the first, G2: the second and G3: the third).

There was significant positive correlation between the index of improvement of soccer-performance quality and the sum-index of how many days each participant followed each of seven contents of intervention ( $\mathrm{p}=0.003$ ) (Fig. 5). In the G1 showing highest performance, there was significant positive correlation between the scores of the diurnal type scale and the index of performance improvement (Morning-typed participants showed improvement of performance) $(\mathrm{p}=0.003)$. In $\mathrm{G} 3$ which ranked the third in accordance with total performance ability, mental health was improved by the no usage of PC at night during the intervention period of one month (Pearson's correlation test: $\mathrm{r}=0.64, \mathrm{p}=0.001, \mathrm{n}=22$ ) (Fig. 6). Improvement of mental health indicated by "irritation" and "anger", due to the intervention for one month was mainly shown in G1 and G2 (Fig. 7). Significant improvement was shown only in G2 which ranked the second in accordance with total performance ability (Wilcoxon-test: Group 1 which ranked the first, $\mathrm{z}=-1.651, \mathrm{p}=0.099$; Group 2, $\mathrm{z}=-2.126, \mathrm{p}=0.033$; Group 3 which ranked the third, $\mathrm{z}=-1.365, \mathrm{p}=0.172$ ) (Fig. 7).

The index of improvement of soccer-performance quality showed significantly positive correlation with the days in which TV-game was not used at night during the intervention one month (Pearson's correlation test: $\mathrm{r}=-0.43$, $\mathrm{p}=0.003, \mathrm{n}=46$ ) (Fig. 8). This improvement of soccer-performance due to no-use of TV-game at night was neither mediated through the diurnal type scale, sleep quality and mental health (ANOVA: $\mathrm{df}=13, \mathrm{~F}=3.57$, $\mathrm{p}=0.002$; ANCOVA: diurnal type scales, $\mathrm{F}=2.94, \mathrm{p}=0.007$; sleep quality, $\mathrm{F}=3.48, \mathrm{p}=0.003$; mental health, 
$\mathrm{F}=3,638, \mathrm{p}=0.002$ ). Probably, a "direct" neuropsychological damage due to night time TV-game use might relate to the prevention of soccer performance improvement.

\section{Discussion and Conclusion}

The first two interventions and the third intervention using this leaflet would be effective to improve the performance of athletes via changing them into the morning-typed persons. The improvement of sports performance is based on the following three physiological mechanisms.

The first two interventions were performed in the fall of 2008 and 2010. In The All Japan Inter College Soccer Tournament for Prime Minister Cup in 2003-2007, Kochi University soccer team was defeated in the first round. However, the team marked the third, the second and $8^{\text {th }}$ place in 2008, 2009 and 2010, respectively. The participation of the series of intervention program might have some possibility to take a contribution to these wonderful results.

1) Sufficient growth hormone secretion due to early bedtime can repair the physical damage due to training, and athletes could have healthful physical conditions in which they are hard to be injured during training and game.

Growth hormone secretion peak has been coincided with the appearance of deep Non-REM sleep with slow wave due to EEG, and growth hormone releasing hormone can decrease wakefulness and increase SWS in human and rats (Cauter \& Plat, 1996). These two phenomena were enhanced by cortisol application (Bohlhalter et al., 1997).

This means "Go to bed early" promotes higher secretion of growth hormone in athletes.

Saceda et al. (2011) reported that growth hormone application promotes the peripheral nerve regeneration in rats. In general, growth hormone seems to accelerate immunological power (Hattori, 2009) and the repairmen of peripheral organs in adult humans.

2) New skills fixation as memory in the brain during REM sleep at the following night.

REM sleep has a function of the fixation of memorized issues in the brain (Fogel et al., 2007; Smith, 2012). Skills in sports which are newly taken during the training could be fixed in the brain during REM sleep in the last half of the sleep hours in the next night of the training day.

3) High concentration of serotonins in the daytime brain which can promote the concentration on the play in the training and game for the athletes.

The protein rich breakfast and following exposure to sunlight can promote the serotonin synthesis in the brain in the morning and the serotonin seems to increase the concentration on the play during the training and game.

The results of the three intervention studies on soccer team members of Kochi University showed the possibility to improve the performance of sports through promoting sleep health and morning-typed life. Detailed 7 contents in the leaflet would be powerful for promoting physical and mental health of athletes in the world.

\section{References}

Atkinson, G., \& Davenne, D. (2007). Relationships between sleep, physical activity and human health. Physiology \& Behavior, 90, 229-235. http://dx.doi.org/10.1016/j.physbeh.2006.09.015

Bohlhalter, S., Murck, H., Holsboer, F., \& Steiger, A. (1997). Cortisol enhances non-REM sleep and growth hormone secretion in elderly subjects. Neurobiology of Aging, 18, 423-429. http://dx.doi.org/10.1016/S0197-4580(97)00036-5

Brand, S., Gerber, M., Beck, J., Hatzinger, M., Pühse, U., \& Holsbore-Trachsler, E. (2010). Exercise levels are related to favorable sleep patterns and psychological functioning in adolescents: A comparison of athletes and controls. Journal of Adolescent Health, 46, 133-141. http://dx.doi.org/10.1016/j.jadohealth.2009.06.018

Burgess, H. J., Sletten, T., Savic, N., Gilbert, S. S., \& Dawson, D. (2001). Effects of bright light and melatonin on sleep propensity, temperature, and cardiac activity at night. Journal of Applied Physiology, 91, 1214-1222. Retrieved from http://www.jap.org

Cauter, E. V., \& Plat, L. (1996). Physiology of growth hormone secretion during sleep. The Journal of Pediatrics, 128(Supplement), S32-S37. http://dx.doi.org/10.1016/S0022-3476(96)70008-2

Deniau, E., \& Cohen, D. (2005). Selective serotonin reuptake inhibitors in childhood and adolescent depression: Recent controversies. Psychiatry Science and Human Neuroscience, 5, 109-116. http://dx.doi.org/10.1007/s11836-007-0023-1 
Fogel, S. M., Smith, C. T., \& Cote, K. A. (2007). Dissociable learning-dependent changes in REM and non-REM sleep in declarative and procedural memory systems. Behavioural Brain Research, 180, 48-61. http://dx.doi.org/10.1016/j.bbr.2007.02.037

Gooley, J. J., Chamberiain, K., Smith, K. A., Khalsa, S. B. S., Rajaratnam, S. M. W., Reen, E. V., Zeitzer, J. M., Czeisler, C. A., \& Lockley, S. W. (2011). Exposure to room light before bedtime suppresses melatonin onset and shortens melatonin duration in humans. The Journal of Clinical Endocrinology \& Metabolism, 96, E463-E472. http://dx.doi.org/10.1210/jc.2010-2098

Harada, T. (2004). Effects of evening light conditions on salivary melatonin of Japanese junior high school students. Journal of Circadian Rhythms, 2, 1-5. http://dx.doi.org/10.1186/1740-3391-2-4

Harada, T., Wada, K., Takeuchi, H., \& Noji, T. (2011). Leaflet entitled “Three benefits due to 'Go to bed early, Get up early and Don't forget breakfast', Message for Ath letes!"

Harada, T., Kadowaki, A., Shinomiya, H., \& Takeuchi, H. (2004). Relationship between watching late night TV and morningness-eveningness of 18-22-year old Japanese students. Sleep and Biological Rhythms, 2, 97-98. http://dx.doi.org/10.1111/j.1479-8425.2003.00076.x

Harada, T., Hirotani, A., Maeda, M., Nomura, H., \& Takeuchi, H. (2007). Correlation between breakfast tryptophan content and morningness-eveningness in Japanese infants and students aged 0-15 yrs. Journal of Physiological Anthropolology, 26, 201-207. http://dx.doi.org/10.2114/jpa2.26.201

Harada, T., Nakade, M., Wada, K., Kondo, A., Maeda, M., Noji, T., \& Takeuchi, H. (2012). Mental health of children from a chronobiological and epidemiological point of view. In V. Olisah (Ed.), Essential Notes in Psychiatry (p. 580). Intech, Rijeka, Croatia. http://dx.doi.org/10.5772/38801

Harada, T., Inoue, M., Takeuchi, H., Watanabe, N., Hamada, M., Kadota, G., \& Yamashita, Y. (1998). Study on diurnal rhythms in the life of Japanese university, junior high and elementary school students including morningness-eveningness preference. Bulletin of the Faculty of Education, Kochi University, 56, 1-91.

Hattori, N. (2009). Expression, regulation and biological actions of growth hormone (GH) and ghrelin in the immune system. Growth Hormone \& IGF Research, 19, 187-197. http://dx.doi.org/10.1016/j.ghir.2008.12.001

Higuchi, S., Motohashi, Y., Liu, Y., \& Maeda, A. (2005). Effects of playing a computer game using a bright display on pre-sleep physiological variables, sleep latency, slow wave sleep and REM sleep. Journal of Sleep Research, 14, 267-273. http://dx.doi.org/10.1111/j.1365-2869.2005.00463.x

Kalak, N., Gerber, M., Kirov, R., Mikoteit, T., Yordanova, J., Pühse, U., Holsboer-Trachsler, E., \& Brand, S. (2012). Daily morning running for 3 weeks improved sleep and psychological functioning in healthy adolescents compared with controls. Journal of Adolescent Health, 51, 615-622. http://dx.doi.org/10.1016/j.jadohealth.2012.02.020

Kubota, T., Uchiyama, M., Suzuki, H., Shibui, K., Kim, K., Tan, X., Tagaya, H., Okawa, M., \& Inoue S. (2002). Effects of nocturnal bright light on saliva melatonin, core body temperature and sleep propensity rhythms in human subjects. Neuroscience Research, 42, 115-122. http://dx.doi.org/10.1016/S0168-0102(01)00310-8

Laakso, M. L., Porkka-Heiskanen, T., Alila, A., Stenberg, D., \& Johansson G. (1990). Correlation between salivary and serum melatonin: Dependence on serum melatonin levels. Journal of Pineal Research, 9, 39-50. http://dx.doi.org/10.1111/j.1600-079X.1990.tb00692.x

Lindström, M. B., Rvding, E., Bossona, P., Ahnlide, J-A., Rosen, I., \& Träskman-Bendz, L. (2004). Impulsivity related to brain serotonin transporter binding capacity in suicide attempters. European Neuropsychopharmacology, 14, 295-300. http://dx.doi.org/10.1016/j.euroneuro.2003.11.001

Linnoila, M., Higley, D., Nielsen, D., Andersen, P., Suomi, S., Goldman, D., \& Virkkunen, M. (1993). Serotonin and impulse control: From clinic to clone. European Neuropsychopharmacology, 3, 161. http://dx.doi.org/1016/0924-977X(93)90001-3

Mahmood, T., \& Silverstone, T. (2001). Serotonin and bipolar disorder. Journal of Affective Disorders, 66, 1-11. http://dx.doi.org/10.1016/S0165-0327(00)00226-3

Monroe, L. J. (1967). Psychlogical and physiological differences between good and poor sleepers. Journal of Abnomal Psychology, 72, 255-264. http://dx.doi.org/10.1037/h0024563 
Moore, P., Landolt, H. P., Seifrizt, E., Clark, C., Bhatti, T., Kelsoe, J., Rapaport, M., \& Gillin, C. (2000). Clinical and physiological consequences of rapid tryptophan epletion. Neuropsychopharmacology, 23, 601-622. http://dx.doi.org/10.1016/S0893-133X(00)00161-5

Nagtegaal, E., Peeters, T., Swart, W., Smits, M., Kerkhof, G., \& Van der Meer, G. (1998). Correlation between concentrations of melatonin in saliva and serum in patients with delayed sleep phase syndrome. Therapeutic Drug Monitoring, 20, 181-183. http://dx.doi.org/10.1097/00007691-199804000-00008

Nakade, M., Takeuchi, H., Taniwaki, N., Noji, T., \& Harada, T. (2009). An integrated effect of protein intake at breakfast and morning exposure to sunlight on the circadian typology in Japanese infants aged 2-6 years. Journal of Physiological Anthropology, 28, 239-245. http://dx.doi.org/10.2114/jpa2.28.239

Nakade, M., Akimitsu, O., Wada, K., Krejci, M., Noji, T., Taniwaki, N., Takeuchi H., \& Harada T. (2012). Can breakfast Tryptophan and Vitamin B6 intake and morning exposure to sunlight promote morning-typology in young children aged 2-6 years? Journal of Physiological Anthropology, 31, 11. http://dx.doi.org/10.1186/1880-6805-31-11

Peuhkuri, K., Sihvola, N., \& Korpela, R. (2012). Dietary factors and fluctuating levels of melatonin. Food \& Nutrition Research, 56. http://dx.doi.org/10.3402/fnr.v56i0.17252

Rosenthal, N., Schwartz, P., Tumer, E., Nalm, S., Matthews, J., Hardin, T., Barnett, R., \& Wehr, T. (1997). The psychobiology of SAD and the mechanism of action of light therapy. Biological Psychiatry, 42, 57S. http://dx.doi.org/10.1016/S0006-3223(97)87120-X

Saceda, J., Isla, A., Santiago, S., Morales, C., Odene, C., Hernandez, B., \& Deniz, K. (2011). Effect of recombinant human growth hormone on peripheral nerve regeneration: Experimental work on the ulnar nerve of the rat. Neuroscience Letters, 504, 146-150. http://dx.doi.org/10.1016/j.neulet.2011.09.020

Shinomiya, H., Takeuchi, H., Martoni, M., Natale, V., \& Harada, T. (2004). Comparative study on circadian typology of Japanese and Italian students aged 12-18 years. Sleep and Biological Rhythms, 2, 93-95. http://dx.doi.org/10.1111/j.1479-8425.2003.00075.x

Smith, C. (2012). Sleep states, memory processing, and dreams. Sleep Medicine Clinics, 7, 455-467. http://dx.doi.org/10.1016/j.jsmc.2012.06.008

Suzuki, E. (2000). Serotonin and nerve cells, the brain and drugs (pp. 41-42). Seiwa Shoten, Tokyo.

Takahashi, K., Yoshimura, Y., Kagimoto, T., Kunii, D., Komatsu, T., \& Yamamoto, S. (2001). Validation of a Food Frequency Questionnaire based on food groups for estimating individual nutritionintake. Japanese Journal of Nutrition and Dietetics, 59, 221-232. http://dx.doi.org/10.5264/eiyogakuzashi.59.221

Takeuchi, T., Nakade, M., Wada, K., Akimitsu, O., Krejci, M., Noji, T., \& Harada, T. (2012). Can an integrated intervention on breakfast and following sunlight exposure promote morning-type diurnal rhythms of Japanese University sports club students? Sleep and Biological Rhythms, 10, 255-263.

Taylor, S., \& Murray, B. (2006). The future of selective serotonin reuptake inhibitors (SSRIs) in psychiatric treatment. Medical Hypotheses, 66, 14-21. http://dx.doi.org/10.1016/j.mehy.2005.08.035

Torsvall, L., \& Åkerstedt, T. (1980). A diurnal type scale: Construction, consistency and validation in shift work. Scandinavian Journal of Work, Environment \& Health, 6, 283-290. http://dx.doi.org/10.5271/sjweh.2608

Van Praag, H. M. (2001). Anxiety-/Aggression-driven depression: A paradigm of functionalization and verticalization of psychiatric diagnosis. Progress in Neuro-Psychopharmacology \& Biological Psychiatry, 25, 893-924. http://dx.doi.org/10.1016/S0278-5846(01)00151-8

Wada, K., Yata, S., Akimitsu, O., Krejci, M., Noji, T., Nakade, M., Takeuchi, H., \& Harada, H. (2013). A tryptophan-rich breakfast and exposure to light with low color temperature at night improve sleep and salivary melatonin level in Japanese students. Journal of Circadian Rhythms, 11, 4. http://dx.doi.org/10.1186/1740-3391-11-4

Yoshimura, Y., \& Takahashi, K. (2007). FFQg: Food frequency Questionnaire Based on Food Groups. Kenpakusha Co., Tokyo.

Zhang, X., Beaulieu, J. M., Sotnikova, T. D., Gainetdinov, R. R., \& Caron, M. G. (2004). Tryptophan hydroxylase-2 controls brain serotonin synthesis. Science, $305,217$. http://dx.doi.org/10.1126/science.1097540 


\section{Copyrights}

Copyright for this article is retained by the author(s), with first publication rights granted to the journal.

This is an open-access article distributed under the terms and conditions of the Creative Commons Attribution license (http://creativecommons.org/licenses/by/3.0/). 